\title{
AN INTERNATIONAL SECURITY EDUCATION PERSPECTIVE
}

\author{
Gerald Quirchmayr \\ Universität Wien, Fakultät für Informatik, Liebiggasse 4/4-6, A-1010 Wien, Austria and \\ University of South Australia, School of Computer and Information Science, Mawson Lakes, \\ SA-5095, Australia
}

\begin{abstract}
The intended contribution of this paper is to motivate the need for an internationalization of IT security education. Starting from the existing situation and a look at selected existing concepts, the paper then presents an idea for international security education cooperation at a doctoral level
\end{abstract}

Key words: IT security education, international cooperation, doctoral programs.

\section{INTRODUCTION AND BACKGROUND}

There is an obvious need to introduce minimal standards in the field of IT security. Today, the situation is very unfortunate in that no internationally accepted minimal standard for IT security knowledge exists. There however are national attempts, mostly following the "core body knowledge" principle in several countries. Curricula suggestions of ACM, IEEE, ACS and many other computer societies clearly recommend a minimal security education for all IT and IS students. With these organizations and advanced universities driving the development, a reasonable standard could be established in the leading universities of the industrialized world. The problem of very few tertiary educational institutions offering a specialization in IT security however still remains to be solved. Ambitious groups and institutions around the world, which the US National Information Assurance Training and Education Center (NIATEC) the European Erasmus/Socrates partnerships of universities carrying out research-oriented education in IT security (Katsikas \& Gritzalis 2000) and the nascent cooperation in this field 
between universities who are partners in the Australian Technology Network (www.atn.edu.au) indicate that the need of educational cooperation on the national and international is beginning to be met. The primary motivation behind this cooperation is easy to explain. It is becoming more and more difficult to cover the whole area of IT security as single educational institution. There are a few examples of universities that can sustain postgraduate programs in IT security on their own, but this is rather exceptional.

\section{WHAT ARE THE NEEDS, WHERE ARE THE MODELS TO FOLLOW?}

As mentioned in the introduction there are very few attempts towards the internationalization of IT security education, the most promising perhaps being the activities being developed inside the European Union. The scale of the projects and their resources might be considerably smaller than national programs, but their conception is truly international. Successful cooperation on curriculum design, joint development of course content, development of a credit transfer system that works across several countries, and the exchange of staff and students have amply demonstrated that this cooperation is possible. When comparing these initiatives with work that is planned or already carried out on the national level in the US and Australia, it becomes obvious that the intentions of these activities are very similar.

The major motivation is to as quickly as possible spread new knowledge and develop the next generation of IT security experts, which, due to the developing threats, must be far larger than the comparatively small group we have today (see the efforts of the IPICS programs). With probably the only exception being defense, all sectors are coping very badly with the effects of attacks and the need to rethink their approach to systems design, implementation and operation. Government agencies and some selected civilian industry sectors, namely banking and finance, are starting to develop and implement the right responses.

The experience of the past decade has clearly shown that while undergraduate education can be provided, a truly research-oriented education that produces the experts needed for developing tomorrow's solutions, can, like in all other fields of science, only be provided in an international setting. That is why the few existing large-scale networks in the US and on the European level will determine most of the future research outcome. It is very specific to IT security that the success of research education is also closely linked to national interests. That is why truly international cooperation will always be somewhat limited and why currently the only tight cooperation 
model being followed in practice is the one being applied inside the European Union.

\section{DEVELOPING A COMMON RESARCH AGENDA BACKED BY DOCTORAL LEVBEL EDUCATION}

Whatever different views on IT security the involved core players (governments, industry, and education) might have, the need for closer research and educational cooperation becomes evident when looking at the many different aspects of IT security. Probably no single institution can claim to have top experts in fields being as disparate as law, sociology, psychology, and business at one end and cryptography and operating system, network and database security at the other. That is why, especially in universities in the European Union, a more realistic approach was developed. It does admittedly add to the cost of running programs to move students and staff around the continent, but given the urgent need of networking the present and future generations of IT security experts and building expert teams, the return on the investment made can be expected to be very high. Pooling knowledge and human resources is the only way of meeting the future requirements. In spite of attack patterns becoming more and more advanced, the number of successful attacks in relation to the number of attacks launched has dropped steeply. This trend justifies the sometimes quite heavy investments made in the past and gives IT security experts at least some of the much needed time to breathe.

It is at this stage important to identify possible future threats and to start developing respective answers. Crime trend analysis and crime development forecasts, as used by criminologist for many decades, seem to be an appropriate paradigm to work from. Combined with the monitoring of technology trends, this gives an indication of the sort of problems we will be exposed to in the coming years. A research agenda can clearly be developed from such a scenario, but such a scenario-based analysis can also be used to define the educational needs. Meeting these educational needs will in turn produce the experts and researchers needed to master the future challenges.

\section{MOVING TOWARDS AN INERNATIOANL RESEARCH EDUCATION PROGRAM}

As the arguments discussed in the previous sections have shown, the need for an international cooperation at the upper end of research-oriented education clearly exists. 
Given that a not too small number of bureaucratic obstacles will occur and that acts of political will like the EU's Bologna Declaration (Hackl 2001) will not quickly be repeated on a worldwide level, harmonization of content rather than the regulation of programs is the obvious answer.

We basically have to consider four interesting types of programs, the traditional research-oriented Master and $\mathrm{PhD}$ programs and the recently more and more popular professional Master and Doctoral programs. Cooperation in the traditional research programs is most easily established by appointing international colleagues as supervisors or co-supervisors and by allowing students to spend one term or one academic year in the middle of their studies at a partner institution (sandwich approach). Provided that there are mutual benefits and that the exchange is no one way system, this type of cooperation is rather easy to handle.

The real challenge is to establish a collaboration model suitable for professional programs that are to a substantial extent based on coursework. The challenges will range from the agreement on the content of courses and their accreditation to their required number and the duration of the program. The experience with cooperating at the level of Master programs across several disciplines in the European Union has shown that, unless two institutions have very similar academic structures and programs, the crossaccreditation of modules or individual courses is the only sustainable alternative.

\section{WHAT CAN WE BUILD ON?}

Luckily enough academics around the globe can in our field build on having successfully cooperated in the past, be it in the organization of conferences, joint research projects, or staff exchange programs. As essential as this personal basis is, it cannot replace more institutionalized approaches. When left to single institutions the resulting number of different models of cooperation might easily lead to a chaotic situation. Building on existing national (NIATEC, ATN) and international networks (IFIP) therefore is the most promising way of moving towards an organized form of cooperation. Pioneering models like the Erasmus/Socrates one, which is now applied in approximately 30 European countries, can serve as base to start from.

In a first step it is however essential to identify relevant national and international models for academic cooperation and accreditation that already exist and are suitable. 


\section{CONCLUSION}

National as well as international cooperation in the field of IT security research education is still in its infancy, but successful pioneering efforts made in the US, Europe and Australia are indicating that especially universities at the cutting edge of technology are driving towards establishing the necessary environment. It is only a matter of time for these advanced groups to join forces and establish mutually accredited research and professional education frameworks. With the increasing need for national and international cooperation in the area of cyber crime prevention it is definitely not a minute too early to start thinking about establishing educational standards to assure that experts participating in joint efforts can count on their partners having the right level of expertise. It is obviously research and development projects that will benefit first, but the positive impact on industry and government cannot be denied, e.g. in cyber crime prevention and IT forensics.

\section{RECOMMENDED RESOURCES}

NIATEC:http://cob.isu.edu/schou/niatec.htm

NCISSE: http://www.ncisse.org

ATN: http://www.atn.edu.au

IPICS: http://www.tol.oulu.fi/kurssit/811327A/IPICS2004.htm

(Hackl 2001) Elsa Hackl, Towards a European Area of Higher Education: Change and Convergence in European Higher Education. EUI Working Papers, Rsc. No. 2001/09. European University Institute, Badia Fiesolana, I-50016 San Domenico (FI), Italy.

(Katsikas \& Gritzalis 2000) Katsikas S., Gritzalis D. (Eds.), A proposal for a postgraduate programme on information and communication systems security, European Commission, SOCRATES \& Youth TAO, Report IS-CD-4b, Athens, January 2000. 